\title{
Vitamin D Supplementation is Beneficial for Children with Autism Spectrum Disorder: A Meta-analysis
}

\author{
Liyao Song ${ }^{1, *}$, Xiaomei Luo ${ }^{1, *}$, Qing Jiang ${ }^{1}$, Zhi Chen ${ }^{2}$, Lifang Zhou', Dan Wang ${ }^{1}$, Ai Chen ${ }^{1,3}$ \\ ${ }^{1}$ Department of Pediatrics, ${ }^{2}$ Nursing Department, The Affiliated Hospital of Southwest Medical University, Luzhou, ${ }^{3}$ Department of Pediatric, \\ Sichuan Provincial Hospital for Women and Children, Chengdu, Sichuan Province, China
}

\begin{abstract}
Objective: We conducted a meta-analysis of randomized controlled trials to explore whether vitamin D supplementation is beneficial for symptom improvement in children with autism spectrum disorder.

Methods: We systematically searched the PubMed database, EMBASE, Cochrane Library, Web of Science, Sino-Med, Wanfang Data, and China National Knowledge Infrastructure mainly up to September 2019. Using a fixed effects model, we calculated the standard mean difference with 95\% confidence interval. Furthermore, we analyzed baseline serum 25-hydroxyvitamin D levels and outcome scores including the Social Responsiveness Scale and Child Autism Rating Scale scores after vitamin D supplementation.

Results: There was no significant difference in baseline serum 25-hydroxyvitamin D levels among 203 children included from three studies in the meta-analysis. After vitamin D supplementation, the outcome scores in the experimental group were dramatically elevated compared with those in the control group ( $p=0.03$ ).

Conclusion: Vitamin D supplementation improves the typical symptoms of autism spectrum disorder, as indicated by reduced Social Responsiveness Scale and Child Autism Rating Scale scores; thus, it is beneficial for children with autism spectrum disorder.
\end{abstract}

KEY WORDS: Vitamin D; Children; Autism spectrum disorder; Meta-analysis.

\section{INTRODUCTION}

Autism spectrum disorder (ASD) is a neurodevelopmental disorder characterized by social, communicative, and behavioral deficits. Its clinical manifestations include indifference, communication rejection, language development retardation, and repeated behavioral stereotypes $[1,2]$. ASD comprises different subgroups based on the child's primary symptoms, such as autism, Asperger's syndrome, and other unspecified generalized developmental disorders (Pervasive Developmental Disorder-Not Otherwise Specified) [1]. In the late 1990s, the prevalence of ASD was less than 60 per 10,000 people, and approximately

Received: August 28, 2019/ Revised: October 3, 2019

Accepted: December 2, 2019

Address for correspondence: Ai Chen

Department of Paediatrics, The Affiliated Hospital of Southwest

Medical University, Kang-Jian Area, Kangcheng Avenue, Taiping

Road, Jiangyang District, Luzhou, Sichuan Province 646000, China

E-mail: zuoma78@163.com

ORCID: https://orcid.org/0000-0003-3120-4949

*These authors contributed equally to this study as co-first authors.
$30 \%$ of the affected individuals were children [3-5]. The incidence of ASD has increased gradually $[6,7]$, and the current prevalence is approximately $90-250$ per 10,000 individuals [8-11]. Therefore, early detection of ASD is essential for treatment and prevention.

The etiology of autism remains unclear. Previous studies have focused on genetic factors, brain disease, and neurobiological factors, among others. ASD is the result of interaction between genetic and environmental factors [12]. However, hereditary factor has always been considered to be the dominant factor $[13,14]$. Genetic studies have shown that dizygotic twins have a concordance rate of approximately $31 \%$ for ASD. Surprisingly, monozygotic twins with identical DNA only have a concordance rate of approximately $88 \%$ for ASD $[15,16]$. Furthermore, findings from twin studies suggest that the prenatal environment can influence the incidence of autism. For instance, Godar and Merrill [17] proposed that low vitamin D3 levels or viral infection of the uterus can potentially alter the prenatal environment, leading to

(c) This is an Open-Access article distributed under the terms of the Creative Commons Attribution Non-Commercial License (http://creativecommons.org/licenses/by-nc/4.0) which permits unrestricted non-commercial use, distribution, and reproduction in any medium, provided the original work is properly cited. 
the development of ASD.

Low serum vitamin D levels are a confirmed environmental risk factor for autism, not only in childhood but also during the fetal period $[18,19]$. Vitamin D plays an important role in the human nervous system and is associated with the prevention of depression [20-24], epilepsy [25-29], schizophrenia [30,31], Alzheimer's disease [32,33], Parkinson's disease [34,35], and multiple sclerosis $[30,36]$. The activated form of vitamin $D$, that is, 1,25-dihydroxy vitamin $\mathrm{D} 3\left(25[\mathrm{OH}]_{2} \mathrm{D}_{3}\right)$, is a steroid with strong endocrine, paracrine, and autocrine effects. It participates in the synthesis of neurotrophic factors and enzymes related to the synthesis of neurotransmitters and in the inhibition of the synthesis of inducible nitric oxide synthase; furthermore, it plays a role in nourishing the nerves and increasing glutathione levels. Therefore, it plays an extensive role in the brain detoxification pathway [36].

Vitamin D binds to more than 2,700 genes and regulates the expression of more than 200 of these genes [37-39]. It is necessary for regulating serotonin production [40]. More importantly, vitamin D increases estrogen levels in the placenta and brain $[41,42]$. Estrogen is vital for brain development [43]; this may explain why males have a four to five times higher risk of autism than females [44]. Notably, patients with ASD exhibit abnormal regulation of estrogen receptor and estrogen receptor coactivators in the middle frontal gyrus in the brain [45]. In addition, the combination of in vivo, in vitro, and animal model data provides a convincing basis for the important role of vitamin $\mathrm{D}$ in neuronal cell proliferation, differentiation, neuroprotection, neurotransmitter transmission, and neuroplasticity $[46,47]$.

A decade ago, Cannell [18] first proposed a correlation between vitamin $\mathrm{D}$ and ASDs. However, few studies have analyzed symptom improvement in children with ASD after vitamin D supplementation. Therefore, we performed a multicenter meta-analysis to provide further evidence on this.

\section{METHODS}

\section{Search Strategy}

This meta-analysis evaluated the association between vitamin D supplementation and symptom improvement in children with autism. Data were collected from the
PubMed database, EMBASE, Cochrane Library, Web of Science, Sino-Med, Wanfang Data, and China National Knowledge Infrastructure (CNKI) mainly up to September 2019. The search was conducted using the main terminology. Different search strategies were adopted for different databases. The specific search strategy is presented in Figures $1-3$.

\section{Inclusion and Exclusion Criteria}

Inclusion criteria for studies collected for the metaanalysis were as follows: (1) studies on children with ASD diagnosed according to the International Classification of Diseases (ICD-9 and ICD-10) and the Diagnostic Statistical Manual of Mental Disorders (DSM-4 and DSM-5); (2) studies including children aged $\leq 18$ years; (3) studies in which specific serum vitamin $D$ levels were directly investigated; (4) studies reporting significant differences in vitamin D levels after intervention; (5) studies in which vitamin D supplementation was the intervention; and (6) studies which were randomized controlled trials.

Exclusion criteria were as follows: (1) studies with participants having any disease that could affect serum vitamin D levels and (2) the article type being a meta-analysis, observational study, review study, letter to the editor, or case report.

\section{Data Extraction and Quality Assessment}

The title, abstract, and full text of studies were independently screened by two researchers. Unrelated studies were excluded. Specific screening procedures are de-

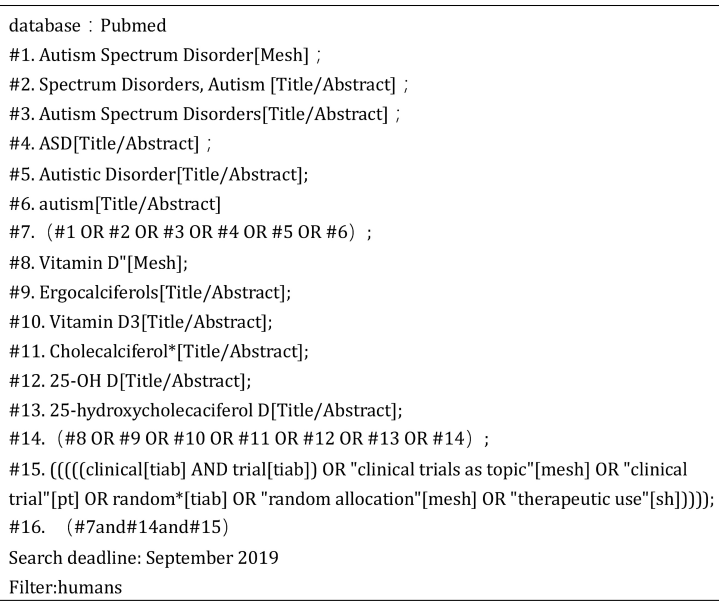

Fig. 1. Search strategy for PubMed. 


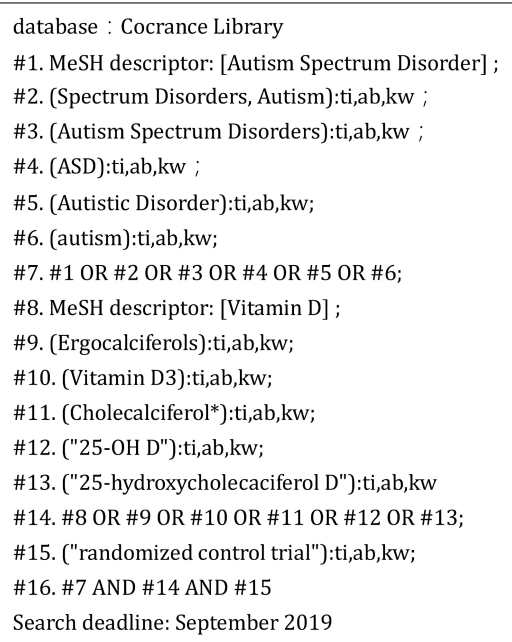

Fig. 2. Search strategy for Cochrane Library.

scribed in the "Description of studies" in the result section. Any disagreement between the two screening researchers was resolved through discussion between them or through evaluation by a third reviewer to reach a final decision. The reasons for exclusion of articles were recorded. The data collected from the relevant studies included the following: (1) general information: first author, publication year, research country, study design, and sample size; (2) specific intervention: the dose and duration of vitamin D supplementation; (3) precise data: the mean and standard deviation values as well as the related $p$ values of vitamin D levels and outcome scores on score sheet, among others. In total, three studies were included in this meta-analysis. The Cochrane bias test was used to evaluate randomized controlled trials (RCTs).

\section{Statistical Analysis}

The outcomes were analyzed using the Review Manager version 5.3 (The Nordic Cochrane Centre, The Cochrane Collaboration, Copenhagen, Denmark). Considering that data to be analyzed in this study have different units, data on $25(\mathrm{OH})$ D levels and Social Responsiveness Scale (SRS) and Child Autism Rating Scale (CARS) scores were analyzed using the standardized mean difference (SMD) with 95\% confidence interval $(\mathrm{Cl})$. Statistical heterogeneity was quantified using $\mathrm{Q}$ test and $l^{2}$ statistic. Significant heterogeneity was suggested as $p<0.10$ or $I^{2}>$ $50 \%$. If $p>0.1$ and/or $I^{2}<50 \%$, the fixed effects model was used to test the combined effect; otherwise, the ran-

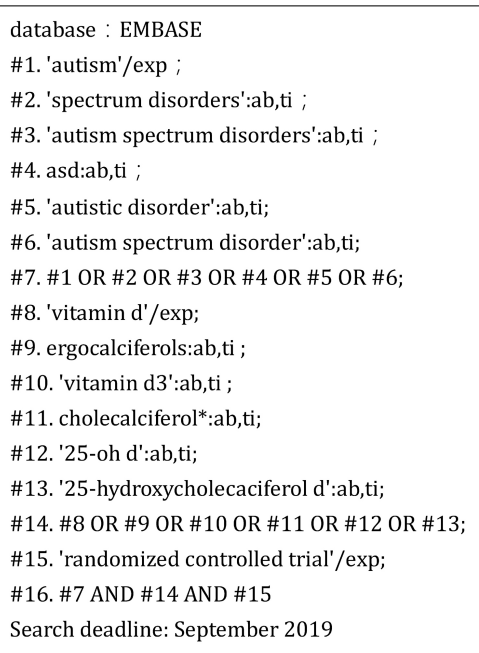

Fig. 3. Search strategy for EMBASE.

dom effects model was adopted.

\section{RESULTS}

\section{Description of Studies}

In total, 452 studies were retrieved after searching the databases and other ways (contact the author or check out newspapers and magazines) mainly up to September 2019. Of the 452 studies, 264 were from PubMed, with the filter of humans; 130 from Web of Science, 19 from EMBASE, 17 from Cochrane Library, 6 from Wanfang data, 14 from CNKI, and 2 from Sino-Med. Following the elimination of 37 duplicated articles, 33 articles were obtained by initial screening of the title and abstract. After browsing the full text, 29 articles (case-control study [n = 12], multiple research objects $[n=6]$, mixed intervention $[n=4]$, open-label trial [ $n=4]$, no ending data [ $n=2]$, and inappropriate inclusion criteria $[n=1])$. Notably, one of the articles [48], both in terms of research design and final analysis, was tremendously consistent with this meta-analysis. However, the included children with autism had serum vitamin D levels $<30 \mathrm{ng} / \mathrm{ml}$, which was inconsistent with the inclusion criteria of the present study; therefore, it was excluded. After full text screening, four RCT articles met the inclusion criteria; however, among them, the article of Saad et al. [49] was retracted because the validity of the research results was not demonstrated $[50,51]$. Ultimately, three RCTs were included in the analysis. Figure 4 presents the selection process. In 


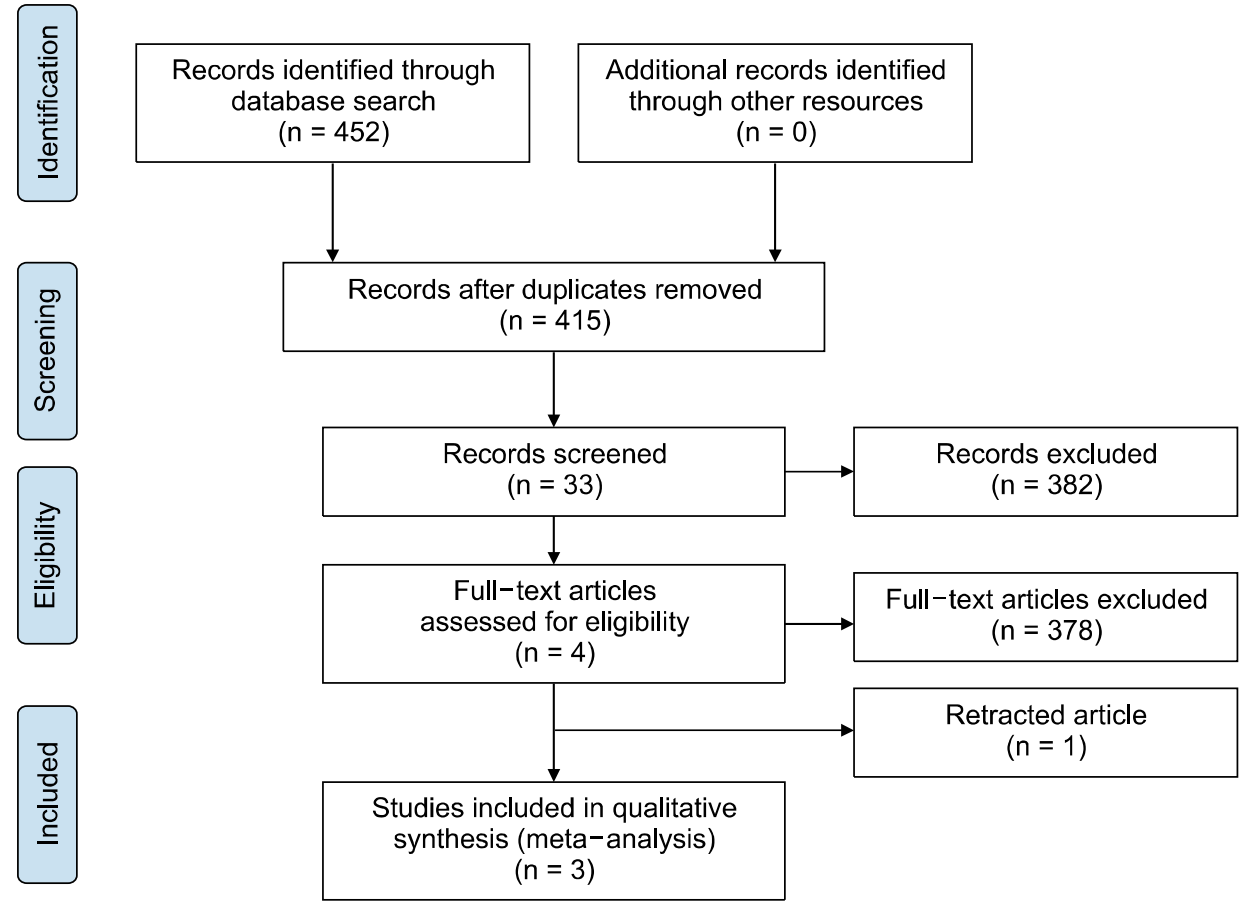

Fig. 4. Selection process of this study. this meta-analysis, all data relevant to vitamin D and ASD were extracted; the extracted data included sample size, age, sex, serum vitamin D levels, vitamin D supplement dose and duration, and outcome indicators. The basic characteristics of the included studies are shown in Table 1.

\section{Serum Vitamin D Levels}

Baseline serum vitamin D levels of both the experimental and control groups in the three studies included in this meta-analysis were recorded. We only selected the data on vitamin D group and placebo group, neglecting unrelated information such as that on omega-3 group and vitamin D + omega-3 group, in the studies of Fang et al. [52] and Mazahery et al. [53,54]. Results showed that there were no significant differences in baseline serum vitamin D levels between the experimental and control groups in the three included studies $(\mathrm{SMD}=0.3,95 \% \mathrm{Cl}=$ -0.06 to $0.65 ; p=0.1)$, and low heterogeneity was noted among the three studies $\left(I^{2}=0 \%\right)$ (Fig. 5).

\section{Outcome Scores on Score Sheet}

Two of the three articles used the Aberrant Behavior Checklist (ABC) and SRS scale scores as outcome indicators, whereas the other article used the CARS score as the indicator. The scores on these three evaluation scales can comprehensively represent the severity degree of symptoms in children with ASD. Among these three scales, evaluation indexes partially coincide with each other, and SRS and CARS scores are assigned in the same way, which is rather different from that for the ABC scale. Furthermore, the CARS score before the trial was not recorded in Fang's article [52]. Therefore, SRS and CARS scores after vitamin D supplementation were used as the outcome index in the present study.

The fixed effects model was used because there was no heterogeneity between CARS and SRS scores $\left(\chi^{2}=1.7, \mathrm{df}=2\right.$, $\left.r^{2}=0 \% ; p=0.43\right)$. The results showed that the total effect amount fell on the left side of the invalid line, and test group intervention was considered favorable. Additionally, the mean vitamin D level was higher in the test group than in the placebo group. Thus, vitamin D supplementation was found to be a favorable factor for symptom improvement in children with autism $(\mathrm{SMD}=-0.46,95 \% \mathrm{Cl}:-0.87$ to $-0.05 ; p=0.03$; Fig. 6).

\section{Publication Bias}

Demographic information and additional details extracted from the included studies are summarized in Table 1. The Cochrane Handbook for Systematic Reviews of Interventions was used to evaluate the studies, except two studies: Kerley's study [55], which did not describe the randomization algorithm, and Fang's analysis [52], which 


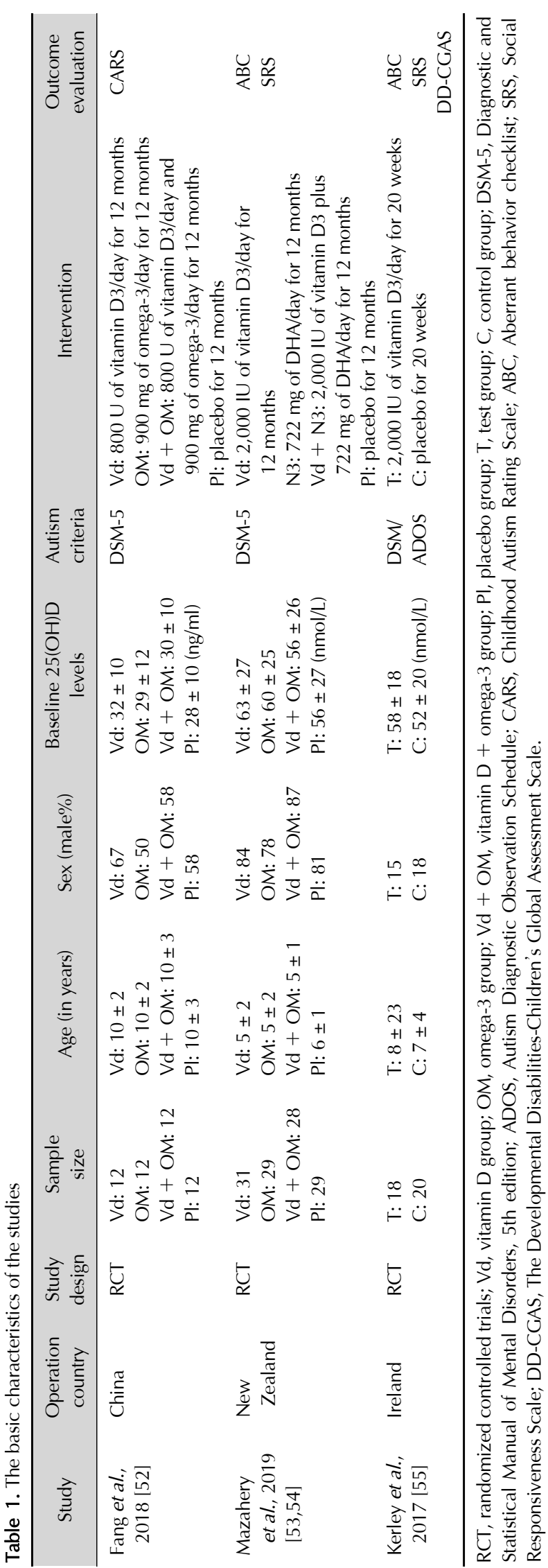

did not describe the specific process and may have had other biases. Most studies qualified by meeting the following requirements: (1) provided clear inclusion and exclusion criteria, (2) proposed a randomization methodology, (3) stated allocation concealment, (4) used a double-blind approach in all RCT groups, and (5) demonstrated complete outcome data (Figs. 7, 8).

\section{Sensitivity Analyses}

Sensitivity analysis of baseline serum vitamin D levels was performed by reanalyzing the remaining literature after removing references one by one. Same result was obtained for each analysis. No heterogeneity was observed, and the total benefit was intersected with the invalid line. In the sensitivity analyses for the scores, the outcome indicators, the same method was followed, and it was found that the heterogeneity remained unchanged. Although some results showed that the total effect amount intersected the invalid line, most of the total effect amounts consistently fell on the left side of the invalid line. Together, these two similar findings indicate that the results of this meta-analysis had a relatively low sensitivity and the total performance was reliable.

\section{Publishing Bias}

According to the recommendations of the Cochrane Handbook, if a funnel chart is used for publication bias evaluation, the number of studies included in the index should not be less than 10 . Otherwise, considerably few studies will be included in the index, leading to a decline in the inspection ability of the funnel chart; thus, the authenticity of the asymmetry would not be judged. The research indicators of this study did not reach 10 articles; hence, no funnel plot analysis of publication bias was performed.

\section{DISCUSSION}

This study is the first meta-analysis to explore the effect of vitamin D supplementation on children with ASD. We conducted a meta-analysis of three RCTs including 203 children with ASD who were assigned to receive either vitamin D supplementation or a placebo. The results suggest that appropriate vitamin $\mathrm{D}$ supplementation is beneficial for symptom improvement in children with ASD, as demonstrated by reduced SRS and CARS scores. 


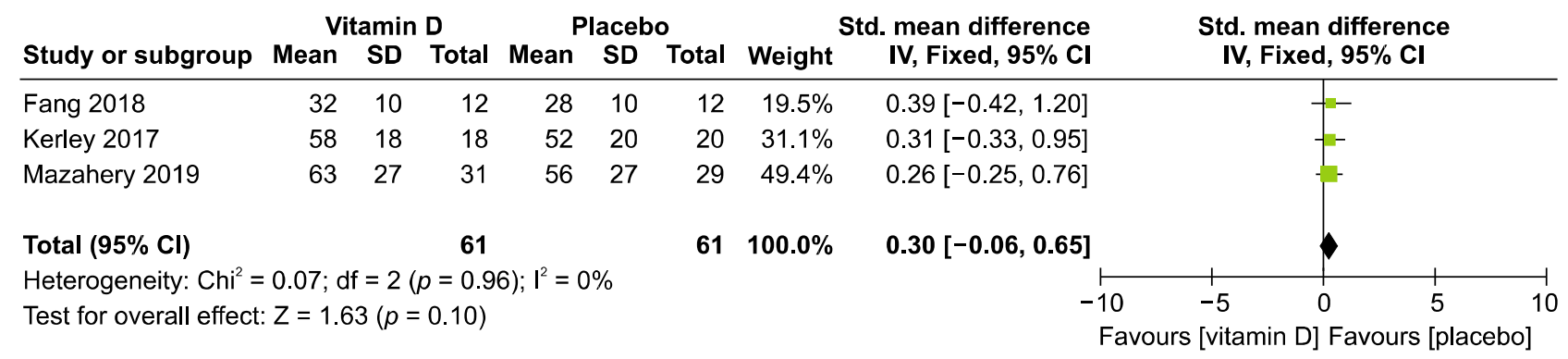

Fig. 5. Forest plot of comparisons of baseline $25(\mathrm{OH}) \mathrm{D}$ levels.

$\mathrm{SD}$, standard deviation; IV, inverse variance; $\mathrm{Cl}$, confidence interval.

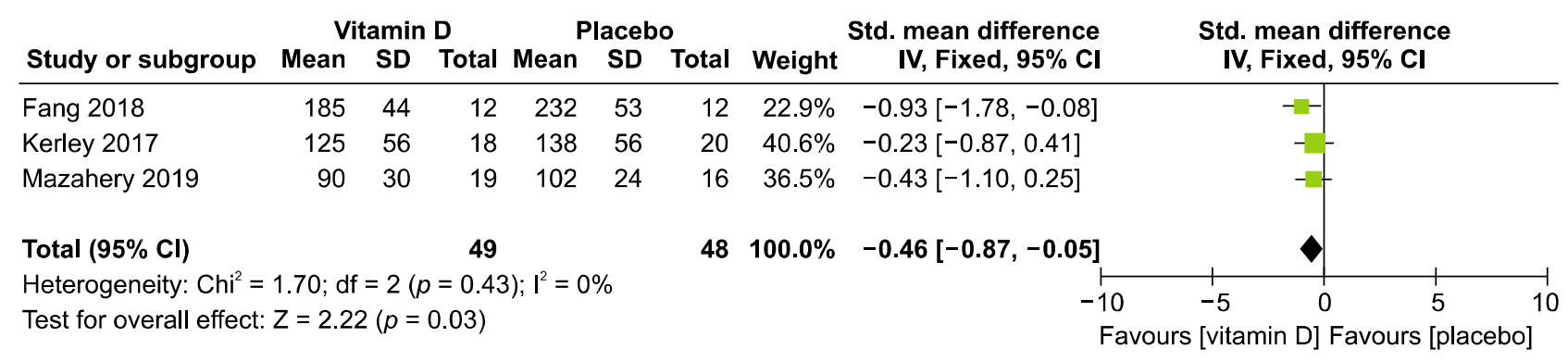

Fig. 6. Forest plot of comparisons of the scores of outcome indicator.

$\mathrm{SD}$, standard deviation; IV, inverse variance; $\mathrm{Cl}$, confidence interval.

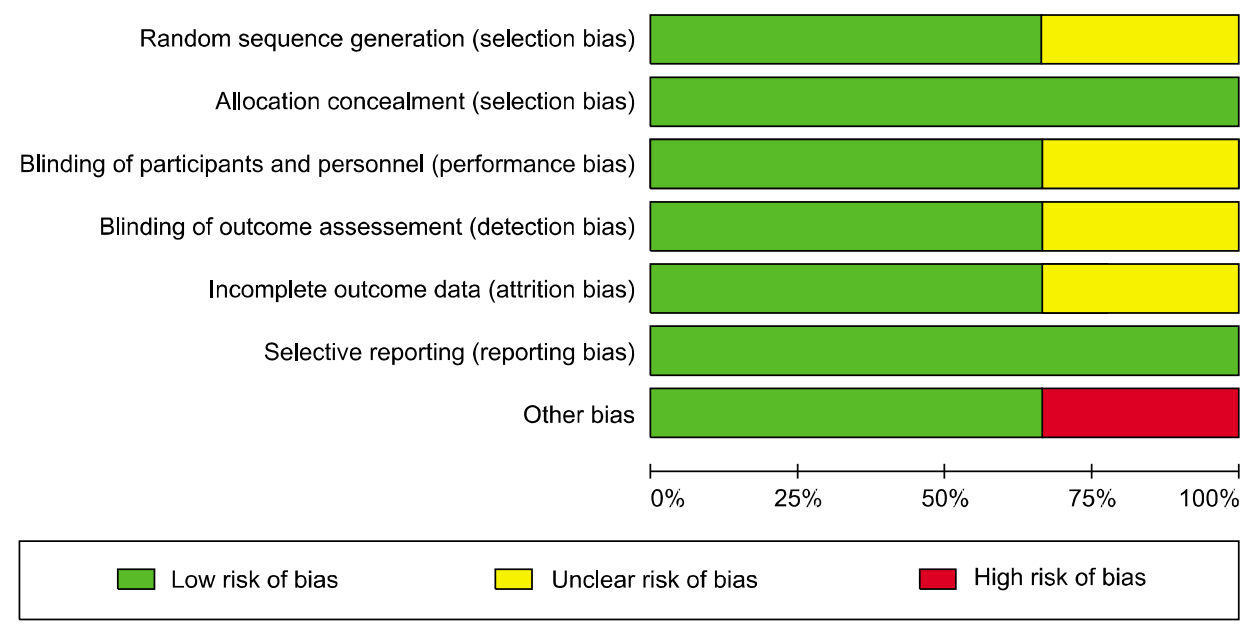

Fig. 7. Risk of bias of the three randomized controlled trials (RCT) studies.
Previous studies do not provide clear evidence to prove that vitamin D supplementation can result in symptom improvement in children wish ASD. However, our results are supported by the finding of a significant number of researchers who have reported that low serum vitamin D levels are a risk factor for ASD both in the fetal life and during childhood.

Two series of articles $[56,57]$ revealed that serum vitamin D levels in children with ASD were significantly lower than those in healthy children, and a significant corre- lation was found between these levels and various core symptoms of ASD. Saad et al. [39] concluded that among 122 children with ASD, 57\% had vitamin D insufficiency and $30 \%$ had vitamin D deficiency; meanwhile, $80.72 \%$ children were treated with vitamin D3, resulting in dramatic improvement. Coincidentally, other related studies [58-63] have also reached the same conclusion, that is, serum vitamin $\mathrm{D}$ levels in children with autism are significantly lower than those in control group. Moreover, the study of Mostafa and Al-Ayadhi [60] found a negative 


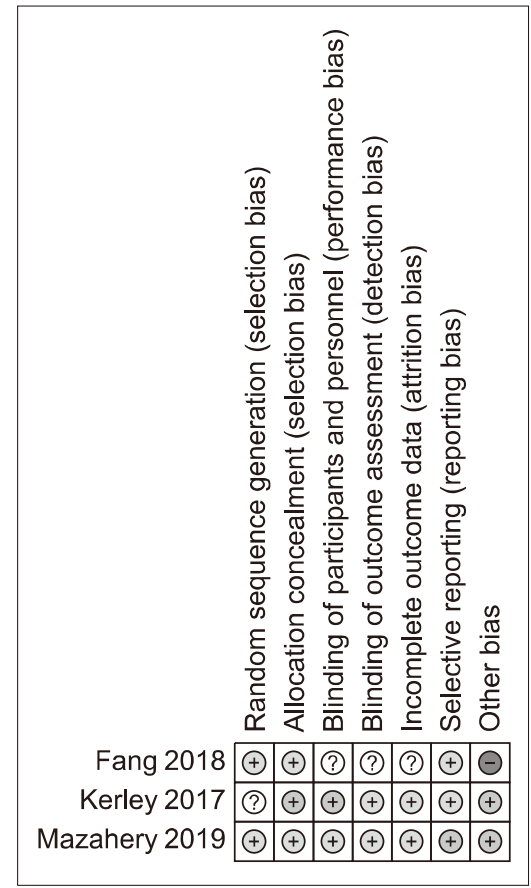

Fig. 8. Risk of bias of the three randomized controlled trials (RCT) studies.

association between autism severity and serum vitamin D levels.

Adams et al. [64,65] found that nutritional and metabolic statuses of children with autism improved after supplementation with vitamins and minerals in their daily diet. In an year-long study, Infante et al. [66] suggested that a combination of omega-3 and vitamin D supplementation could effectively improve the core symptoms in children with autism. Saad et al. [49] found a significant symptom improvement after appropriate vitamin D supplementation in children with autism. However, Kerley et al. [67] found that when children with autism and those with asthma received the same dose of vitamin D simultaneously, the increase in serum 25(OH)D levels in children with autism remained significantly smaller than that in children with asthma in the control group even after being supplemented for a longer duration.

Studies [68-71] have also emphasized that lack of vitamin D during pregnancy is associated with autism after birth. Stubbs et al. [71] conducted a study on mothers of children with autism; the mothers received vitamin D supplementation during pregnancy, and the babies received it during neonatal period. The results showed that autism developed in 1 in 19 cases (5\%); the occurrence rate was clearly lower than the theoretical reported rate of $20 \%$ [72].

Through the considerable research mentioned above, we observed the same phenomenon, that is, children with autism have lower serum vitamin D levels than normal children.

Such observation prompted us to complete this research. Before conducting this study, only few case-control studies and one meta-analysis were available to provide strong evidence regarding this observation. Wang et al. [61] conducted a meta-analysis and screened 11 case-control studies, obtaining 870 patients with autism and 782 healthy controls; they concluded that patients with autism had lower serum vitamin D levels than the healthy control group patients. However, this is only an observational study with insufficient argument and no mention of the topic we are concerned with.

Low serum vitamin D levels in children with ASD may be due to insufficient intaken and an increased consumption. Some children with ASD may have other diseases that possibly affect vitamin D absorption and transformation in the body. Additionally, geographical reasons and living habits associated with insufficient exposure to sunlight may hinder vitamin D absorption. Vitamin D is extremely important for human nervous system. It aids in the synthesis of neurotrophic factors and enzymes, nourishment of the nerves, secretion of neurotransmitters, and fusion and regulation of gene expression, among others $[46,47]$. Therefore, a proper dose of vitamin D supplements may play a beneficial role in the development of the nervous system, thereby improving the symptoms of autism. These insights are merely reasonable speculations, and more research is needed to confirm this conclusion.

In the analysis of baseline serum vitamin D levels, the obtained result intersected with the ineffective line; the difference in the baseline levels was not significant, and the study was comparable. Under this premise, the difference in SRS and CARS scores after vitamin D supplementation both in the experimental and control groups was taken as the indicator. The results showed that the diamond fell on the left side of the invalid line. Furthermore, the studied factors are beneficial to the occurrence of the outcome, implying that vitamin D supplementation is a protective factor for children with ASD.

Regarding sensitivity analysis, the total effect amount was consistent with the current result, but in some results, 
the total effect amount intersected with the invalid line. In any case, each analysis result showed that the majority of the total effect amount fell on the left side of the invalid line. It means that vitamin D supplementation is absolutely harmless to children with autism and may have a certain improvement effect.

However, this meta-analysis is limited by the number and level of existing clinical trials. The authors' level and objective conditions are also limited, and the search scope makes it difficult to cover all relevant literature, thereby reducing the intensity of the research demonstration to some extent. Thus, more favorable evidence remains to be confirmed by conducting more high-quality, large-sample clinical trials or meta-analysis in the future.

\section{Acknowledgments}

All the data were consulted on the website, and we have not used the human body materials or data that can identify the identity information. The research project does not involve personal privacy and commercial interests.

We thank the Affiliated Hospital of Southwest Medical University for financial support in this study.

This work was supported by the Sichuan Provincial Health and Family Planning Commission (Grant/Award Number: 15018), Southwest Medical University (Grant/Award Number: 201710; JG2018096), Department of Education of Sichuan Province (Grant/Award Number: 17ZB0470), Sichuan Provincial Department of Education-Sichuan Medical Law Research Center (Grant/Award Number: YF18-Y26).

\section{Conflicts of Interest}

No potential conflict of interest relevant to this article was reported.

\section{Author Contributions}

Conceptualization: Zhi Chen, Data acquisition: Qin Jiang, Lifang Zhou, Dan Wang, Formal analysis: Liyao Song, Funding: Ai Chen, Supervision: Ai Chen, Writingoriginal draft: Liyao Song, Xiaomei Luo, Writing-review \& editing: Liyao Song, Ai Chen.

\section{ORCID}

Liyao Song https://orcid.org/0000-0001-9876-0013

Xiaomei Luo
Qin Jiang

Zhi Chen

Lifang Zhou

Dan Wang

Ai Chen
https://orcid.org/0000-0001-9421-797X

https://orcid.org/0000-0002-8005-2307

https://orcid.org/0000-0002-0887-7451

https://orcid.org/0000-0003-2128-2599

https://orcid.org/0000-0003-3120-4949

\section{REFERENCES}

1. American Psychiatric Association. Diagnostic and statistical manual of mental disorders. 5th ed. Washington D.C.:American Psychiatric American Psychiatric Association;2013.

2. Abdallah MW, Greaves-Lord K, Grove J, Nørgaard-Pedersen B, Hougaard DM, Mortensen EL. Psychiatric comorbidities in autism spectrum disorders: findings from a Danish historic birth cohort. Eur Child Adolesc Psychiatry 2011;20:599-601.

3. Fombonne E. Epidemiological surveys of autism and other pervasive developmental disorders: an update. J Autism Dev Disord 2003;33:365-382.

4. Fombonne E. Epidemiology of pervasive developmental disorders. Pediatr Res 2009;65:591-598.

5. Chakrabarti S, Fombonne E. Pervasive developmental disorders in preschool children. JAMA 2001;285:3093-3099.

6. Atladottir HO, Gyllenberg D, Langridge A, Sandin S, Hansen $\mathrm{SN}$, Leonard $\mathrm{H}$, et al. The increasing prevalence of reported diagnoses of childhood psychiatric disorders: a descriptive multinational comparison. Eur Child Adolesc Psychiatry 2015;24:173-183.

7. Mazahery H, Camargo CA Jr, Conlon C, Beck KL, Kruger MC, von Hurst PR. Vitamin $D$ and autism spectrum disorder: a literature review. Nutrients 2016;8:236.

8. New Zealand Guidelines Group. What does ASD look like?: New Zealand autism spectrum disorder guideline: a resource to help identify autism spectrum disorder. Wellington:New Zealand Guidelines Group;2010.

9. Autism and Developmental Disabilities Monitoring Network Surveillance Year 2008 Principal Investigators; Centers for Disease Control and Prevention. Prevalence of autism spectrum disorders--Autism and Developmental Disabilities Monitoring Network, 14 sites, United States, 2008. MMWR Surveill Summ 2012;61:1-19.

10. Ghanizadeh A. A preliminary study on screening prevalence of pervasive developmental disorder in schoolchildren in Iran. J Autism Dev Disord 2008;38:759-763.

11. Kogan MD, Blumberg SJ, Schieve LA, Boyle CA, Perrin JM, Ghandour RM, et al. Prevalence of parent-reported diagnosis of autism spectrum disorder among children in the US, 2007. Pediatrics 2009;124:1395-1403.

12. Kim YS, Leventhal BL. Genetic epidemiology and insights into interactive genetic and environmental effects in autism spectrum disorders. Biol Psychiatry 2015;77:66-74.

13. Smalley SL, Asarnow RF, Spence MA. Autism and genetics. A decade of research. Arch Gen Psychiatry 1988;45:953-961.

14. Tick B, Bolton P, Happé F, Rutter M, Rijsdijk F. Heritability of 
autism spectrum disorders: a meta-analysis of twin studies. J Child Psychol Psychiatry 2016;57:585-595.

15. Rosenberg RE, Law JK, Yenokyan G, McGready J, Kaufmann WE, Law PA. Characteristics and concordance of autism spectrum disorders among 277 twin pairs. Arch Pediatr AdolesC Med 2009;163:907-914.

16. Newschaffer CJ, Croen LA, Fallin MD, Hertz-Picciotto I, Nguyen DV, Lee NL, et al. Infant siblings and the investigation of autism risk factors. J Neurodev Disord 2012;4:7.

17. Godar DE, Merrill SJ. Untangling the most probable role for vitamin D3 in autism. Dermatoendocrinol 2017;9:e1387702.

18. Cannell JJ. Autism and vitamin D. Med Hypotheses 2008;70: 750-759.

19. Vinkhuyzen AAE, Eyles DW, Burne THJ, Blanken LME, Kruithof CJ, Verhulst F, et al. Gestational vitamin D deficiency and autism-related traits: the generation $R$ study. Mol Psychiatry 2018;23:240-246.

20. Schneider B, Weber B, Frensch A, Stein J, Fritz J. Vitamin D in schizophrenia, major depression and alcoholism. J Neural Transm (Vienna) 2000;107:839-842.

21. Hoogendijk WJ, Lips P, Dik MG, Deeg DJ, Beekman AT, Penninx BW. Depression is associated with decreased 25-hydroxyvitamin D and increased parathyroid hormone levels in older adults. Arch Gen Psychiatry 2008;65:508-512.

22. Ganji V, Milone C, Cody MM, McCarty F, Wang YT. Serum vitamin $D$ concentrations are related to depression in young adult US population: the Third National Health and Nutrition Examination Survey. Int Arch Med 2010;3:29.

23. Hoang MT, Defina LF, Willis BL, Leonard DS, Weiner MF, Brown ES. Association between low serum 25-hydroxyvitamin $D$ and depression in a large sample of healthy adults: the Cooper Center longitudinal study. Mayo Clin Proc 2011;86: 1050-1055.

24. Anglin RE, Samaan Z, Walter SD, McDonald SD. Vitamin D deficiency and depression in adults: systematic review and meta-analysis. Br J Psychiatry 2013;202:100-107.

25. Kalueff AV, Minasyan A, Tuohimaa P. Anticonvulsant effects of 1,25-dihydroxyvitamin $D$ in chemically induced seizures in mice. Brain Res Bull 2005;67:156-160.

26. Kalueff AV, Minasyan A, Keisala T, Kuuslahti M, Miettinen S, Tuohimaa P. Increased severity of chemically induced seizures in mice with partially deleted Vitamin D receptor gene. Neurosci Lett 2006;394:69-73.

27. Borowicz KK, Morawska M, Furmanek-Karwowska K, Luszczki JJ, Czuczwar SJ. Cholecalciferol enhances the anticonvulsant effect of conventional antiepileptic drugs in the mouse model of maximal electroshock. Eur J Pharmacol 2007;573:111-115.

28. Borowicz KK, Morawska D, Morawska M. Effect of cholecalciferol on the anticonvulsant action of some second generation antiepileptic drugs in the mouse model of maximal electroshock. Pharmacol Rep 2015;67:875-880.

29. Pendo K, DeGiorgio CM. Vitamin D3 for the treatment of epi- lepsy: basic mechanisms, animal models, and clinical trials. Front Neurol 2016;7:218.

30. McGrath JJ, Eyles DW, Pedersen CB, Anderson C, Ko P, Burne $\mathrm{TH}$, et al. Neonatal vitamin D status and risk of schizophrenia: a population-based case-control study. Arch Gen Psychiatry 2010;67:889-894.

31. Hedelin M, Löf M, Olsson M, Lewander T, Nilsson B, Hultman $\mathrm{CM}$, et al. Dietary intake of fish, omega-3, omega-6 polyunsaturated fatty acids and vitamin $D$ and the prevalence of psychotic-like symptoms in a cohort of 33,000 women from the general population. BMC Psychiatry 2010;10:38.

32. Oudshoorn C, Mattace-Raso FU, van der Velde N, Colin EM, van der Cammen TJ. Higher serum vitamin D3 levels are associated with better cognitive test performance in patients with Alzheimer's disease. Dement Geriatr Cogn Disord 2008;25: 539-543.

33. Annweiler C, Schott AM, Rolland Y, Blain H, Herrmann FR, Beauchet O. Dietary intake of vitamin D and cognition in older women: a large population-based study. Neurology 2010; 75:1810-1816.

34. Evatt ML, DeLong MR, Kumari M, Auinger P, McDermott MP, Tangpricha V. High prevalence of hypovitaminosis D status in patients with early Parkinson disease. Arch Neurol 2011;68: 314-319.

35. Knekt $P$, Kilkkinen A, Rissanen $H$, Marniemi J, Sääksjärvi $K$, Heliövaara M. Serum vitamin $D$ and the risk of Parkinson disease. Arch Neurol 2010;67:808-811.

36. Garcion E, Wion-Barbot N, Montero-Menei CN, Berger F, Wion D. New clues about vitamin D functions in the nervous system. Trends Endocrinol Metab 2002;13:100-105.

37. Ramagopalan SV, Heger A, Berlanga AJ, Maugeri NJ, Lincoln MR, Burrell A, et al. A ChIP-seq defined genome-wide map of vitamin $D$ receptor binding: associations with disease and evolution. Genome Res 2010;20:1352-1360.

38. Cannell JJ, Grant WB. What is the role of vitamin D in autism? Dermatoendocrinol 2013;5:199-204.

39. Saad K, Abdel-Rahman AA, Elserogy YM, Al-Atram AA, Cannell JJ, Bjørklund G, et al. Vitamin D status in autism spectrum disorders and the efficacy of vitamin D supplementation in autistic children. Nutr Neurosci 2016;19:346-351.

40. Kaneko I, Sabir MS, Dussik CM, Whitfield GK, Karrys A, Hsieh JC, et al. 1,25-Dihydroxyvitamin D regulates expression of the tryptophan hydroxylase 2 and leptin genes: implication for behavioral influences of vitamin D. FASEB J 2015;29:40234035.

41. Barrera D, Avila E, Hernández G, Halhali A, Biruete B, Larrea $\mathrm{F}$, et al. Estradiol and progesterone synthesis in human placenta is stimulated by calcitriol. J Steroid Biochem Mol Biol 2007; 103:529-532.

42. Yague JG, Garcia-Segura LM, Azcoitia I. Selective transcriptional regulation of aromatase gene by vitamin $D$, dexamethasone, and mifepristone in human glioma cells. Endocrine 2009;35:252-261. 
43. McCarthy MM. Estradiol and the developing brain. Physiol Rev 2008;88:91-124.

44. Centers for Disease Control and Prevention. Data \& statistics on autism spectrum disorder [Internet]. Atlanta: Centers for Disease Control and Prevention [cited at 2019 Sep 1]. Available from: https://www.cdc.gov/ncbddd/autism/data.html.

45. Crider A, Thakkar R, Ahmed AO, Pillai A. Dysregulation of estrogen receptor beta (ER $\beta)$, aromatase (CYP19A1), and ER co-activators in the middle frontal gyrus of autism spectrum disorder subjects. Mol Autism 2014;5:46.

46. DeLuca GC, Kimball SM, Kolasinski J, Ramagopalan SV, Ebers GC. Review: the role of vitamin D in nervous system health and disease. Neuropathol App/ Neurobiol 2013;39:458-484.

47. Cannell JJ. Vitamin D and autism, what's new? Rev Endocr Metab Disord 2017;18:183-193.

48. Moradi H, Sohrabi M, Taheri H, Khodashenas E, Movahedi A. The effects of different combinations of perceptual-motor exercises, music, and vitamin D supplementation on the nerve growth factor in children with high-functioning autism. Complement Ther Clin Pract 2018;31:139-145.

49. Saad K, Abdel-Rahman AA, Elserogy YM, Al-Atram AA, El-Houfey AA, Othman HA, et al. Randomized controlled trial of vitamin D supplementation in children with autism spectrum disorder. J Child Psychol Psychiatry 2018;59:20-29.

50. Stevenson J. Letter to the Editor: Unreported statistics lead to unverifiable results in study of vitamin D supplementation in children with autism spectrum disorder - Comment regarding Saad, K., et al. (2016). J Child Psychol Psychiatry 2018;59:e1-e2.

51. Beale DJ. Letter to the Editor: Unreported statistics lead to unverifiable results in study of vitamin D supplementation in children with autism spectrum disorder - Comment regarding Saad, K., et al. (2016). J Child Psychol Psychiatry 2018;59:e1.

52. Fang L, Jiang XM, Huang YK, Sun YX, Xie YF, Wang $L$, et al. Efficacy of vitamin $D$ combined with $\omega-3$ fatty acid in treatment of children with autism spectrum disorder. Pharm Care Res 2018;18:347-350.

53. Mazahery H, Conlon CA, Beck KL, Mugridge O, Kruger MC, Stonehouse W, et al. A randomised-controlled trial of vitamin $D$ and omega-3 long chain polyunsaturated fatty acids in the treatment of core symptoms of autism spectrum disorder in children. J Autism Dev Disord 2019;49:1778-1794.

54. Mazahery H, Conlon CA, Beck KL, Mugridge O, Kruger MC, Stonehouse $\mathrm{W}$, et al. A randomised controlled trial of vitamin $D$ and omega-3 long chain polyunsaturated fatty acids in the treatment of irritability and hyperactivity among children with autism spectrum disorder. J Steroid Biochem Mol Biol 2019; 187:9-16.

55. Kerley CP, Power C, Gallagher L, Coghlan D. Lack of effect of vitamin D3 supplementation in autism: a 20-week, placebo-controlled RCT. Arch Dis Child 2017;102:1030-1036.

56. Dong HY, Wang B, Li HH, Shan L, Jia FY. [Correlation between serum 25-hydroxyvitamin D level and core symptoms of autism spectrum disorder in children]. Zhonghua Er Ke Za
Zhi 2017;55:916-919. Chinese.

57. Absoud M, Lim MJ, Baird G, Meier UC, Kočovská EM. Vitamin-D levels in autism spectrum disorder (ASD) from a population cohort of children. In: The 44th British Paediatric Neurology Association Annual Conference; Jan 3-5, 2018; London, United Kingdom. 59(Supplement 4):10.

58. Gong ZL, Luo CM, Wang L, Shen L, Wei F, Tong RJ, et al. Serum 25-hydroxyvitamin $D$ levels in Chinese children with autism spectrum disorders. Neuroreport 2014;25:23-27.

59. Meguid NA, Hashish AF, Anwar M, Sidhom G. Reduced serum levels of 25-hydroxy and 1,25-dihydroxy vitamin $D$ in Egyptian children with autism. J Altern Complement Med 2010;16:641-645.

60. Mostafa GA, Al-Ayadhi LY. Reduced serum concentrations of 25-hydroxy vitamin $D$ in children with autism: relation to autoimmunity. J Neuroinflammation 2012;9:201.

61. Wang T, Shan L, Du L, Feng J, Xu Z, Staal WG, et al. Serum concentration of 25-hydroxyvitamin $D$ in autism spectrum disorder: a systematic review and meta-analysis. Eur Child Adolesc Psychiatry 2016;25:341-350.

62. Arastoo AA, Khojastehkia H, Rahimi Z, Khafaie MA, Hosseini SA, Mansouri MT, et al. Correction to: Evaluation of serum 25-Hydroxy vitamin D levels in children with autism Spectrum disorder. Ital J Pediatr 2019;45:22.

63. Altun H, Kurutaş EB, Şahin N, Güngör O, Findıklı E. The levels of vitamin $D$, vitamin $D$ receptor, homocysteine and complex $B$ vitamin in children with autism spectrum disorders. Clin Psychopharmacol Neurosci 2018;16:383-390.

64. Adams JB, Audhya T, Geis E, Gehn E, Fimbres V, Pollard EL, et al. Comprehensive nutritional and dietary intervention for autism spectrum disorder-a randomized, controlled 12-month trial. Nutrients 2018;10:E369.

65. Adams JB, Audhya T, McDonough-Means S, Rubin RA, Quig $\mathrm{D}$, Geis $\mathrm{E}$, et al. Effect of a vitamin/mineral supplement on children and adults with autism. BMC Pediatr 2011;11:111.

66. Infante M, Sears B, Rizzo AM, Mariani Cerati D, Caprio M, Ricordi $C$, et al. Omega-3 PUFAs and vitamin D co-supplementation as a safe-effective therapeutic approach for core symptoms of autism spectrum disorder: case report and literature review. Nutr Neurosci 2018. doi: 10.1080/1028415X. 2018.1557385. [Epub ahead of print]

67. Kerley CP, Elnazir B, Greally P, Coghlan D. Blunted serum $25(\mathrm{OH}) \mathrm{D}$ response to vitamin D3 supplementation in children with autism. Nutr Neurosci 2018. doi: 10.1080/ 1028415X.2018.1529342. [Epub ahead of print]

68. Eyles DW, Burne TH, McGrath JJ. Vitamin D, effects on brain development, adult brain function and the links between low levels of vitamin $D$ and neuropsychiatric disease. Front Neuroendocrinol 2013;34:47-64.

69. Grant WB, Soles CM. Epidemiologic evidence supporting the role of maternal vitamin $D$ deficiency as a risk factor for the development of infantile autism. Dermatoendocrinol 2009;1: 223-228. 
70. Noriega DB, Savelkoul HF. Immune dysregulation in autism spectrum disorder. Eur J Pediatr 2014;173:33-43.

71. Stubbs G, Henley K, Green J. Autism: Will vitamin D supplementation during pregnancy and early childhood reduce the recurrence rate of autism in newborn siblings? Med Hypotheses
2016;88:74-78.

72. Ozonoff S, Young GS, Carter A, Messinger D, Yirmiya N, Zwaigenbaum L, et al. Recurrence risk for autism spectrum disorders: a Baby Siblings Research Consortium study. Pediatrics 2011;128:e488-e495. 